\title{
L2 Translation at the Periphery: A Meta-Analysis of Current Views on Translation Directionality ${ }^{1}$
}

\author{
Saber Zahedi \\ Allameh Tabataba'i University
}

\section{Definitions and terminology}

Directionality as defined by Beeby is "whether translators are working from a foreign language into their mother language or vice versa" (84).In this sense, directionality does not mean the direction of translation which exists between source language (SL) and target language (TL), but rather, it refers to the direction between the mother tongue and the foreign tongue of the translator, and thus the product of translation per se does not determine a translation's direction. In order to understand the latter, one should look at the profile of the translator or what Stewart (1999) calls "characteristics or skills of the actual performer of the translation," and whether the translator is working into or out of his native language. However, this does not imply that translation directionality only refers to the flow between one's mother tongue and a foreign language or vice versa; it is also used to refer to translation from a second language to a third, four or even fifth language or vice versa. However, the problem is not so much with the number of languages involved as it is with the diversity of definitions. In Translation Studies, translation into a mother tongue and a foreign language have been termed differently by various scholars, and as Beeby states, "there is no agreement as to the terminology for translation onto the foreign language"(64).

Newmark suggests the expression "service translation" for translation into a foreign language (1988: 3). He defines it as "translation from one's language of habitual use into another language" (52). However, service translation is not a term frequently used by other scholars of translation.

Another expression which is internationally intelligible is "inverse translation". Inverse translation, or in some literature "reverse translation," in essence implies that translation into a foreign tongue is not the direct or natural direction in translation. By contrast, direct translation stands for translation into the mother tongue of the translator. Other terms used to address L2 translation are "prose translation", "theme translation" and "version translation" (Beeby).

${ }^{1}$ I am thankful to Professor Alison Beeby for her helpful comments and suggestions. 
Pavlovic prefers the terms L1 and L2 translation, which she borrows from the field of Second Language Acquisition. In the same vein, Stewart (1999) also prefers to use L1 and L2 translation. The same terminology is used in this study to refer to two different directions of translation.

The various terms historically used for L2 translation have set it apart from the outset, and suggest that it is the ordinary direction of translation. Terms like reverse, inverse, indirect and service translation implicitly suggest that translation flows from L2 to L1, and the reverse is only an exception or a deviation. This derogatory implication in the terminology frequently used for L2 translation is also noted by Pavlovic.

The term native translator, in itself, does not suggest anything in relation to the direction of translation, but it is the underlying assumption of the majority of translators, translation scholars and translation agencies that native-speaker translators are native speakers of the TL.

\section{L2 Translation at the periphery}

Similar to translation scholars, those in the translation market also typically maintain that the correct direction of translation is from the translator's second language to his or her first language. As Stewart mentions, "translation into L2 as a professional activity is outlawed by some renowned authorities in the field" (1999: 41). The following section explores views about translation directionality that are both explicitly and implicitly expressed.

\subsection{Explicitly expressed views}

Explicit opposition to L2 translation is often expressed by directly forbidding L2 translation or recognizing it as imperfect or unnatural. Both of these adjectives need to be defined and elaborated upon. The rule of thumb has it that L1 translation is imbued with naturalness while L2 translation is neither trustworthy nor natural. For instance, Samuelsson-Brown claims that "you may be able to translate quite correctly into a foreign language but it will eventually become evident that the translation was not written by a 'native'."(27)

Newmark (1988:3) advocates the idea that L2 translators' use of second language is not authentic and natural. He believes that L2 translation only happens out of necessity where L1 translators are missing; however, in these cases, the final product should be revised by a native speaker of the target language. This is also noted by Grosman et al who mentions the existing norms of the translation market where a translation produced by a non-native would be evaluated and revised by a native speaker of the TL, "[...] while nobody demands that a target 
language speaker's reading and comprehension of the source text be submitted to a similar testing and checking by a mother tongue speaker of the source text" (as cited in Pavlovic: 9).

Another figure is Duff who disparages L2 translation by mentioning unnaturalness as its main weakness (11). He believes that the unnaturalness of L2 translation is mainly because of interference from the source text (ST). In other words, translation is heavily under the influence of the ST when done into a second language. Therefore, translation should be done by a native speaker who can grasp the suggestive power of words beyond their dictionary meanings. The unnaturalness of $\mathrm{L} 2$ translation is also referred to as a weakness by Crystal, who claims that "on the whole, translators work into their mother tongue (or language of habitual use), to ensure a result that sounds as natural as possible"(344). Gouadec, as well, claims that "[...] only someone translating into his mother tongue can really produce the clear, effective and, above all, naturally flowing language that a native speaker can produce"(90). None of the mentioned authors, however, provide any objective data or research as proof for making such claims. L2 translators are thought to be unable to grasp the feel of the language into which they are translating, thus constantly producing unnatural and unacceptable outputs. An interesting instance is Dollerup, who stipulates that L2 translators can never master a TL in the same way as the native speakers of that language, and thus are "incapable of producing a good translation in the sense that it sounds like an authentic, native text to target language users"(63). Another example is Chesterman, who believes that the unnaturalness of a given target language text is less likely to be noticed by an L2 translator (2004: 38).

A milder view is taken by Marmaridou who looks at the issue of directionality from a cognitive-semantic point of view. She argues that translation into one's mother tongue yields better results than translation into a foreign language since "the conceptual structures of the mother tongue - and target language - are directly and automatically activated, and hence successfully mapped onto the source text in the second language; i.e. directionality of the translation process from target onto source is compatible with general linguistic processing mechanisms"(60-61). This negative attitude toward L2 translation is very common in the writings of Translation Studies scholars (further examples are Baker 68, Klein-Braley 20, Chesterman 2004: 38). Devaluating remarks about L2 translation are not new. For example, Dryden insisted that a translator should be master of both SL and TL. However, perfect knowledge of the TL was mandatory, and if a deficiency was allowed in either, it would be in the original language (i.e. SL). He argued that a defect in SL knowledge could be compensated by a perfect command of the TL while the reverse condition was by no means permissible. 


\subsection{Implicit views}

Doubts regarding L2 translation are not only explicitly expressed by many scholars, but are also implicitly prevalent in their writings. It seems that translation theorists have accepted claims about the imperfection and marginalization of L2 translation, dismissing the fact that translation into a second language is widely practiced in many countries whose languages are of limited diffusion. As Pokorn writes:

The most common approach to the problem of directionality in translation theory is, however, a silent acceptance of the "traditional" conviction of the necessity to translate into one's mother tongue. Most translation theoreticians do not discuss openly the possibility of choosing one's TL in translation; however, they do covertly express their conviction that only translation into one's mother tongue guarantees a good translation.

This could imply that many Western translation theories are founded on the assumption that translators translate into their mother tongue but rarely out of it. Therefore, issues such as training, assessment, experiment and research are addressed with regard to L1 translation. This section will show how this subliminal message puts L1 translation at the center and L2 translation at the periphery of discussions about translation.

In his seminal essay, "the Task of the Translator," Benjamin writes that "it is the task of the translator to release in his own language that pure language which is under the spell of another, to liberate the language imprisoned in a work in his re-creation of that work"(80). Benjamin uses the phrase "his own language" to refer to the translator's native language; his use of this phrase is in contrast to the phrase "foreign language" or "foreign text." From his perspective, a translator, "who has greater reverence for the usage of their own language than for the spirit of the foreign works" (80), is a part of the receiving audience with whom he/she shares the same national and linguistic identity. Therefore, the translator's task, according to Benjamin, appears to be a duty only for L1 translators who translate foreign works into their own language.

The phrase, "own language," has been used repeatedly by some scholars to imply that the language of a translated text is the translator's native language. In relation to the translation of poetry, Dryden says that "No man is capable of translating poetry, who, besides a genius to that art, is not a master of both his author's language, and of his own [...]"(173). Although Dryden does not directly sanctify L1 translation, he takes it for granted that a translator translates into "his own language." The language of the author, therefore, means a language other than the translator's native language. The underlying assumption of these figures is that a translator always translates into his own language. Tratnik unconsciously implies the above idea by saying that "the 
translator may try to search out some existing but forgotten or culturally-suppressed expressions in her/his own language but which may not perfectly align semantically with the original English expressions" (142). It can be also observed in the following lines by Snell-Hornby, from whose point of view translators are non-native speakers of the SL: "As a non-native speaker, the translator might well activate scenes that diverge from the author's intentions or deviate from those activated by a native speaker of the source language (a frequent cause of translation error)" (81).

Known as a postcolonial translator, Levine, unconsciously assumes that translators should translate into their native language. She states that "the translator is secondary, enslaved, nay raped by another's words; the translator does not belong to himself but is alienated from his own language; the author creates himself, the translator remains secret" (as cited in Robinson 59)..In contrast to "own language", the phrase "foreign language" is used to refer to the language from which one translates. However, the opposite rarely happens; no one expects a translator to translate from his own language. Newmark dismisses the importance of the knowledge of a foreign language by stating that "knowing a foreign language and your subject is not as important as being sensitive to language and being competent to write your own language dexterously, clearly, economically and resourcefully" (1988: 3). This saying assumes that in translation, ST is our foreign language and target text (TT) is our native language. For instance, Lefevere states that "considering the relationship between his work and the foreign language, the first rule the translator must follow is not to allow himself anything that would not also be allowed in an original work of the same genre in his native language"(1992/2003: 159). Here, Lefevere takes "original work" and "native language" as an opposing pair, and the original work is written in the foreign language of the translator.

The covert proposition that translator and target audience are of the same cultural and national background can be observed in numerous writings on translation. It seems that L2 translation has turned into an invisible activity in the eyes of translation scholars. All of the above-mentioned scholars tend to accept that translators are native speakers of the TL, and are thus strangers to the SL. Therefore, if we take this as the status quo of the present age of Translation Studies, we are left with the question of why so many translation theorists are sure that translation is always done into the first language of the translator.

\section{Why L1 translation is the preferred direction of translation}

\subsection{Naturalness and L2 translation}

One of the basic criticisms of L2 translation is that it is conventionally assumed to be neither natural nor fluent. This is perhaps due to the prevalent idea that second language speakers lag 
behind native speakers both in terms of language comprehension and production. Some of the early prescriptive writings such as Newmark's (1998) recognized this flaw as the basic error of L2 translators. They believe that translators' lack of second language competence, as well as their L1 interference, results in unnatural translations. Some scholars see the L2 translator's method as a reason for the unnatural language used in an L2 translation. It is often assumed that L1 translators use a freer method of translation, while L2 translators use a more literal one. Tirkkonen-Condit speculates that "novice translators, even when translating into their native language, tend to prefer literal strategies whenever possible" (as cited in Chesterman 2007: 10).

However, it can also be argued that if an L2 translator is not capable of retrieving the sense of the original and reproducing it in an acceptable form of the target language (i.e. his or her second language), then an L1 translator may also be unable to grasp the meaning of the original, thus producing an erroneous translation. Campbell has also made it clear that L1 translators often have difficulties comprehending the ST (57) (see also Kiraly 117). Dimitrova believes that "translation into L1 involves reading in a foreign language, which potentially requires more resources for the comprehension process. This possibly makes inferencing more difficult, or takes cognitive resources away from inferencing, and this can be assumed to be more notable in the case of students."

Rogers' case study on German L1 and L2 translation showed that successful L2 translations were "informatively more reliable" than the least successful L1 translations. However, the L2 renderings lacked a degree of naturalness compared with successful L1 translation.

Another counter argument for the belief in the naturalness of L1 translation is Pokorn's study, which investigated the differences between translations done by native and non-native speakers. The results revealed that both groups of translators made mistakes both in transferring the content and in producing a natural target-language text.

\subsection{Directionality as a socio-political issue}

Sometimes political observations can determine the direction of translation. For example, a preference for translation into the mother tongue could be an inheritance of the German Romantic period. At that time, the nation and its language were closely linked, thus foreigners were not trusted to translate into German, as the hidden essence of language and nation could not be understood by outsiders. As Pokorn notes

Translation should therefore always proceed from foreign languages to one's mother tongue and never vice-versa, since the hidden essence of the target language is not attainable by any foreign speaker. It seems then that the roots of the conviction that we 
can grasp the ungraspable only in our mother tongue, and consequently create a convincing translation only in our native language, stem from this Romantic identification of the transcendental nature of the nation and its language. (25)

Another instance is noted by Navvabi, who reports that in the Mughal period, Jean Plan de Carpin came into Iran together with his entourage to deliver a letter from Pope Innocent IV to Kuyuk Khan. The Persian King wrote a letter in response, but the Persian diplomats did not trust the French priests to translate the letter, and finally translated it with the help of native Persian translators into Latin.

These examples illustrate that political agendas can play an important part in determining the direction of a translation. Spivak's method for translation is a politically committed approach which advocates a certain policy for translation. Although she does not directly prescribe in what direction the translation should be done, her translation politics suggests that translation into English as a postcolonial discursive practice should be done by L2 translators who are part of the colonized community and who can understand the delicate details of the original text. By contrast, the politics of "cannibalism" require that translation be done into the language of the colonized to make the foreigners' power remerge in their own language (see Vieira). In Translation Studies, cannibalism is used as a metaphor to suggest that foreign works be absorbed in the language of the postcolonial South America. Translation from the viewpoint of cannibalists functions as a means of subversion, and happens into their language, but rarely out of it. Therefore, translation into the language of the colonial power can't be explained by this metaphor, and cannibalism is only about the translation into the language of colonized countries.

Ashcroft, Griffiths et al. note how politically committed approaches view translation directionality (215). They declare that "an accepted convention of Translation Studies is that a translation is always more effective if undertaken by a translator in the target language into which the text is being translated. In post-colonial situations, however (such as in India), many translators may be equally fluent in both source and target languages." Their proposition suggests that L2 translation in postcolonial theories of translation is acceptable due to the fluency of the translators in the TL. However, besides fluency, the direction of translation in post-colonial situations is determined by the policies that translators adopt. Many postcolonial scholars write or translate in an effort to fight against or drive out the colonizer. This necessitates a perfect familiarity with the colonized culture, which is a characteristic of a translator who is a native of the colonized culture. 


\subsection{L1 Translation as a prerequisite for some of the existing theories}

Some of the existing translation theories take L1 direction as their premise. For example, Steiner's theory of hermeneutic motion includes four stages, namely: initial trust, penetration, embodiment and restitution. The translator should make a move toward the original (or foreign text), and bring it back home. These moves, back and forth between the home and the foreign text, should all be done by a translator who is a part of the native culture and language. Steiner's theory simply does not match L2 translation. The reason why hermeneutic approaches assume L1 directionality is not because the translation product should be linguistically appropriate but because the very foreignness of the ST feeds their theory. Interpretation, which is a core phenomenon in hermeneutics, becomes more visible when dealing with texts from different linguistic or temporal backgrounds (Hermans). Gadamer believes that "from the structure of translation [is] indicated the general problem of making what is alien our own" (Gadamer, as cited in Hermans 132)

Gadamer also mentions German translators like Hölderlin, whose translation of Sophocles from Greek into German extended the boundaries of his own language. One of the criticisms Panwitz put forward against translators was that "our translators have a far greater reverence for the usage of their own language than for the spirit of the foreign works."

Although not normative in nature, Venuti's notion of invisibility is to a great extent about L1 translation. Because of its focus on Anglo-American space and the notion of transparency, in most cases, it is often reflected through the behavior of the L1 translators who use domestication as an "ethnocentric reduction" of foreign norms and values, and who translate into their own language (20).

[...] in order to produce the effect of transparency in a translated text, in order to give the reader the sense that the text is a window onto the author, translators must manipulate what often seems to be a very resistant material, i.e., the language into which they are translating, in most cases the language they learned first, their mother tongue, but now also their own. (286-287)

\subsection{Translators as importers}

Translators are often seen as the compatriots of the TL audience rather than the ST author, which means that translator and audience share the same cultural and national background. This bond between the translator and his audience is cultural, linguistic and sometimes even ethnic. Cronin puts readers and translators beside each other and suggests that they start out on a new linguistic experience together (267). "The global standing of a literature depends on the efforts of 
those language learners and translators who can stand outside their own language and learn the other language for the purposes of reading, translation, or both." Cronin's statement shows a translator who is ready to venture into other languages to translate from; thus the source language for him is a foreign language. However, a translator can also introduce the works of his own language and culture to foreign countries and literary systems. The interesting point is that his focus is on translators and readers from the same cultural background who can begin to experience other languages.

Eaglestone uses the metaphor of "neighbors" to depict the relationship between the author and translator (and readers) by saying "to translate the neighbor is to turn him/her/it into a category of our own language and so to deny him/her/its otherness" (136).However, he never considers what might happen if a neighbor (L2 translator) translates him/herself for another neighbor (the foreign audience).

Lefevere (1992/2003) expresses the same idea by saying that a translator is a nurturer of his national literary conventions, dismissing the idea that translation could also be carried out into one's second language. He maintains that "the alternative has, of course, been for translators to introduce new forms into their native literatures based on forms they found in the literature to which their originals belonged" (1992/2003: 8). This bond between the translator and the audience of the translation can also be clearly observed when Lefevere writes that "rather, if translators want to really translate items belonging to the original's Universe of Discourse that do not exist in their own, they will have to "coin new expressions, as Cicero advised" (1992/2003: 46). It is taken for granted that the whole culture of the receiving audience is the same as the translator's, and that the original author does not share the same linguistic, ethnic, national background with the translator of his work. Lefevere also re-enforces this as he states that "translators are allowed more liberties on what one might be tempted to call 'the purely linguistic level,' certainly if the translation is not meant to 'represent' the original in the translators' culture, [...]" (1992/2003: 4, emphasis is mine). In relation to the translation of poetry, he mentions that "the translator allows both the foreign literature to influence and further the development of his native literature and the foreign language to enrich his own language" (1975: 391).

Translation theorists tend to assume a national and cultural link between translators and their receiving audience. As a result of this link, translators are seen as importers of foreign cultures, texts and science into their domestic system of language and literature. Godayol states that "when we translate, we desire, above all, 'to name, and thus confer the right to exist' on an original text transposed into our own language and culture" (368). Steiner also believes that "the translator labors to secure a natural habitat for the alien presence which he has imported into his own tongue and natural cultural setting" (356). It is true that translators bring new forces into a literary and linguistic system, but why is this always thought to happen in one direction? A translator can also export his native literary values and forms out of his mother tongue. It can be 
concluded that theorists, L1 translators and the receiving audience form a Self, who see foreign systems and L2 translators as the Other.

\subsection{The distribution of L1 and L2 translators}

Stewart (2011) suggests that disregard for L2 translation in countries with dominant languages such as the US or the UK does not exist in countries whose languages are of limited diffusion. Not all societies are multinational or multilingual, and this means that L1 translators are in short supply. In English-speaking countries where numerous L1 translators actively translate texts into English, there is no need for an L2 speaker of English to translate into English unless the SL is among less known languages. The existence of translators with different mother tongues also makes L1 translation into languages other than English possible. That is perhaps why some Anglo-American scholars look down on L2 translation, and at the same time assume that translation directionality is almost always from the second language into the mother tongue. However, in countries such as Iran, where Persian is the majority language and there are only very few English native-speakers, translation into English and other foreign languages can only be done by L2 translators. Translation teachers and theorists in countries where translators are often obliged to work in both directions are well aware that L2 translation is widely practiced in both the technical and literary fields.

\section{Reconsidering the state of translation directionality}

There are certain points and aspects of directionality that have not received enough attention in Translation Studies. This issue could be addressed by taking the following points into consideration.

\subsection{The role of technology and pedagogy}

New teaching methodologies and IT-enhanced documentation strategies have changed the nature of the process and product in L2 translation. Traditional translation theories may need to be amended in order to take into account the important influence of pedagogy and technology. Baker's and Newmark's (1988) assumptions might hold true for the traditional stereotype of a translator who worked by candlelight with a pile of papers and books, but the translator's workplace has changed. The use of various dictionaries and resources, computer-aided translation, corpora and the existence of academic training has increased the quality of translations (see Zanettin and Kelly) and it is therefore no longer safe to assume that L2 translation is a naive process resulting in unnatural TTs. This is best put by Chesterman who believes that 
Non-native translators can make good use of quantitative information, banks of comparable non-translated texts, to make their own use of the target language more natural, and they can run tests to check the naturalness of aspects of their translations. This facility may lead to the gradual blurring of the distinction between native and non-native translators at the professional level, which in turn should have an influence on assumptions held by many translation theorists about the exclusive status of translation into the native language.(2004: 46)

McAlester lists some tools such as corpora and machine translation which can facilitate the acceptability of an L2 translation product. She states that translation into the L1 is a translation meme whose enforceability is waning as the need for translation and intercultural exchange greatly outnumbers L1 translators.

\subsection{The level of translators}

Research on directionality should make a careful distinction between novice and professional translators. In other words, the effect of language competence and translation experience on the quality of translation should not be confused with the impact of translation direction. The characteristics of L1 and L2 translation are different in professional and novice translation, and it seems simplistic to think that interference happens equally among novice and professional translators. Therefore, any generalization should be made carefully and in light of objective data.

\subsection{The translation process and directionality}

Many of the comparative details that differentiate L1 and L2 translation have gone unnoticed by traditional translation scholars due to their prescriptivism or lack of process-oriented research. A deeper understanding of the nature of L1 and L2 translation could be gained by undertaking process-oriented research. ${ }^{2}$

\subsection{Directionality as a language-based issue}

It could be speculated that directionality issues are language-based and cannot be generalized. This is especially the case when translation is between English as the lingua franca of our age and other languages. The amount of exposure to English and the quality of its teaching is by no means comparable with other languages. The hegemony of English, therefore, has affected views on directionality. The shared ethnic and linguistic background of English translators, audiences

${ }^{2}$ For more discussion on process-based research into translation directionality, see Pavlovic and Jensen, and Hirci 2012. 
and translation theorists makes it less likely that English theorists will imagine situations where translation is done by an L2 translator, a situation which is common in other countries and language pairs.

\section{Conclusion}

Beliefs about translation directionality among translation theorists and agencies indicate an existing skepticism towards L2 translators. L2 translation was and is still branded by some as unnatural and imperfect. In this respect, translation into the second language is not the ordinary direction of translation, and thus is placed at the periphery while L1 translation is normal and central.

In this article, these views were divided into two types of discourse. The former includes a wave of prescriptivism and underestimation which at the same time idealizes L1 translation and bans translation into the second language. The latter implicitly suggests that the correct, natural and prevalent direction of translation is into the translator's mother tongue. This implicit discourse is fed by the presumption that translator and audience are of the same socio-cultural and linguistic background, that the translator imports into his linguistic and literary system, and finally that he/she always translates into his/her own language.

The roots of the marginalization of L2 translation can be explained in different ways. L2 translation is most commonly condemned as unnatural, and this weakness is evident in the translation of idioms, collocations and fixed expressions (see Newmark 1988 and Baker). The presumed unnaturalness of L2 translation is normally attributed to the translator's poor language production skills due to the difficulties of translating into a second language. However, neither translation theory nor translation itself takes place in a vacuum. They are both affected by various biases and motives. Directionality is a part of this polyvocal discourse. Thus, there is more behind the idealization of L1 translation as the natural direction of translation than mere observation of linguistic issues.

Advocating L1 translation can be explained in some cases by looking at the scholar's theory of translation. This particularly holds true for those who object to free translation methods. Venuti, Benjamin and Berman see the translator as part of a target culture, and his or her main duty is to respect the foreignness of the original text. Steiner's four motions require the existence of a translator who, like a soldier, enters the land of foreigners and brings captives back to his homeland.

Some of the theorists who prescribe L1 translation belong to a country where there is no shortage of L1 translators. It seems that a part of their undervaluation of L2 translation is 
because there has been no need for L2 translators within their country. The opposite is true in countries where the distribution of information to foreign countries is only possible through L2 translation. A real example of how information is exported through the translator's L2 can be seen in scientific papers where the author needs to address her/his audience in English as a lingua franca. In English-speaking countries scientific papers are hardly ever translated since authors can write their papers in their mother tongue and even if the author is not an English native speaker and needs help, the translation is usually carried out by an English L1 translator due to the availability of native translators.

Traditional views on directionality in translation have, to a certain degree, neglected some facts and points which need to be taken seriously. Today, translations often pass through the hands of revisers, and translators are assisted by numerous technological tools which increase the quality of translations. Researchers should also take into account translators' experience and language competence, the translation method, the translation process and the language pair.

Considering all the above-mentioned points, we can conclude that translation quality is not only a matter of directionality, since translation as a mental behavior is very complex and hardly predictable. Translation into one's second language, despite the current opposition, is a necessary and common practice, and as Kearns states, "the reputation of inverse translation is in urgent need of rehabilitation." Objective data and unbiased research are the keys to revealing the undiscovered details of L2 translation. L2 translation, however, should not be studied only with regard to the psychological aspects of translation or the quality of the products, but also with regard to the socio-cultural issues affecting translation directionality to find out if L2 translation has been rejected or accepted as a normal direction on grounds other than quality issues. 


\section{REFERENCES}

AIIC. "Conference Interpretation Glossary." 2012. $<$ http://www.aiic.net/glossary/default.cfm?ID $=49>$.

Ashcroft, Bill, Gareth Griffiths, and Helen Tiffin. Postcolonial Studies: The Key Concepts. London, New York: Routledge, 2007.

Baker, Mona. In Other Words. London, New York: Routledge, 1992/2011.

Beeby Londsdale, Alison. "Direction of Translation (Directionality)." Routledge Encyclopedia of Translation Studies. Eds. Mona Baker and Gabriela Saldanha. London, New York: Routledge, 2009. 63-67.

Benjamin, Walter. "The Task of the Translator.."Illuminations. Trans. Harry Zohn Ed. Hannah Arendt. New York: Random House, Inc., 1923/1968. 63-82.

Berman, Antoine. "Translation and the Trials of the Foreign" The Translation Studies Reader. Ed. and Trans. Lawrence Venuti. 276-289, 1985/2004.

Campbell, Stuart. Translation into the Second Language. London, New York: Longman, 1998.

Chesterman, Andrew. "Beyond the Particular." Translation Universals: Do They Exist? Ed. Anna Mauranen. Amsterdam and Philadephia: John Benjamins, 2004. 33-50.

Chesterman, Andrew. "What Is a Unique Item?" Doubts and Directions in Translation Studies. Eds. Yves Gambier, Miriam Shlesinger and RadegundisStolz. Amsterdam, Philadelphia: John Benjamins, 2007. 3-14.

Cronin, Michael. "Downsizing the World: Translation and the Politics of Proximity." Beyond Descriptive Translation Studies: Investigations in Homage to Gideon Toury. Eds. Anthony Pym, Miriam Shlesinger and Daniel Simeoni. Amsterdam, Philadelphia: John Benjamins, 2008. 265-76.

Crystal, David. The Cambridge Encyclopedia of Language. Cambridge: Cambridge University Press, 1987. 
Dimitrova, Birgitta Englund. Expertise and Explicitation in the Translation Process. Amsterdam, Philadelphia: John Benjamins, 2005.

Dollerup, Cay. "English: Axes for a Target Language." Translation into Non-Mother Tongues in Professional Practise and Training. Eds. Meta Grosman, et al. Tübingen: StauffenburgVerlag, 2000. 61-70.

Dryden, John. "The Three Types of Translation. From "Preface" to Ovid's Epistles." Western Translation Theory: From Herodotus to Nietzsche. Ed. Douglas Robinson. Manchester: St. Jerome, 1680/1997. 171-75.

Duff, Alan. Translation. Oxford: Oxford University Press, 1989.

Eaglestone, Robert. "Levinas, Translation, and Ethics." Nations, Language and the Ethics of Translation. Eds. Sandra Berman and Michael Wood. Princeton: Princeton University Press, 2005. 127-38.

Godayol, Pilar. "Maria-MercèMarçal: (Re)Presentation, Textuality, Translation." Less Translated Languages. Eds. Albert Branchadell, and Lovell Margaret West. Amsterdam, Philadelphia: John Benjamins 2005. 365-74.

Gouadec, Daniel. Translator as a Profession. Amsterdam, Philadelphia: John Benjamins 2007.

Hermans, Theo. "Hermeneutics." Routledge Encyclopedia of Translation Studies. Eds. Mona Baker, and Gabriela Saldanha. London, New York: Routledge, 2009. 130-32.

Hirci, Nataša. "Electronic Reference Resources for Translators. Implications for Productivity and Translation Quality." The Interpreter and Translator Trainer (ITT) 6.2 (2012): 219-35.

Kearns, John. "Challenging the Traditional Axioms. [Review of Pokorn 2005]." 2006. Web. Dec 2012. <http://linguistlist.org/issues/17/17-187.html>.

Kelly, Dorothy. A Handbook. for Translator Trainers. Manchester, Northampton: St. Jerome, 2005. 
Kiraly, Donald C. "Translation into a Non-Mother Tongue: From Collaboration to Competence." Translation into Non-Mother Tongues in Professional Practice and Training. Eds. Meta Grosman et al. City of Publication: Publisher,2000.

Klein-Braley, Christine. "Teaching Translation in Universities: Present and Future Perspectives." Teaching in Professional Practice and Training. Eds. Ian Higgins and Penelope Sewell. London: AFLS and CILT, 1996. 15-30.

Lefevere, André. "The Translation of Poetry: Some Observations and a Model." Comparative Literature Studies 12.4 (1975): 384-92.

Lefevere, André. Translation/History/Culture. London, New York: Routledge, 1992/2003.

Marmaridou, Sophia S.A. "Directionality in Translation Processes and Practice." Target 8.1 (1996): 49-73.

McAlester, Gerar. "The Evaluation of Translation into a Foreign Language." Developing Translation Competence. Eds. Christina Schäffner and Beverly Adab. Amsterdam, Philadelphia: John Benjamins, 2005. 229-41.

Navvabi, Davud. Tarikhe Tarjome AzFarance Be Farsi Dar Iran AzAghaz Ta Konun [The History of Translation from French to Persian in Iran from Beginning to End]. Tehran: Kavian, 1985.

Newmark, Peter. Text Book of Translation. New York, London, Singapore: Prentice Hall, 1988.

Newmark, Peter. Paragraphs on Translation. Multilingual Matters Limited. City of Publication: Publisher, 1989.

Niranjana, Tejaswini. Siting Translation: History, Post-Structuralism, and the Colonial Context. Los Angeles and California: University of California Press, 1992.

Pavlović, Nataša. "Directionality in Collaborative Translation Processes." Diss. Universitat Rovirai Virgili, 2007. 
Pavlović, Nataša, and Kristian Jensen. "Eye Tracking Translation Directionality." Translation Research Projects 2. Eds. Anthony Pym, and Perekrestenko Alexander. Tarragona: Intercultural Studies Group, 2009.

Pokorn, Nike K. Challenging the traditional axioms. Translation into a non-mother tongue. Amsterdam and Philadelphia: John Benjamins Publishing Company, 2005.

Robinson, Douglas. What Is Translation?: Centrifugal Theories, Critical Interventions. Kent: Kent State University Press, 1997.

Rogers, Margaret. "Native Versus Non-Native Speaker Competence in German-English Translation: A Case Study." In and out of English: For Better, for Worse? Eds. GunillaAnderman and Margaret Rogers. Clevedon, Buffalo, Toronto: Multilingual Matters Ltd, 2005. 256-74.

Samuelsson-Brown, G. A Practical Guide for Translators. Multilingual Matters. City of Publication: Publisher, 2010.

Snell-Hornby, Mary. Translation Studies: An Integrated Approach. Amsterdam, Philadelphia: John Benjamins. 1988/1995.

Spivak, Gayatri Chakravorty. Outside in the Teaching Machine. London, New York: Routledge, 1993.

Steiner, George. After Babel: Aspects of Language and Translation. London, Oxford, New York: Oxford University Press, 1975.

Stewart, Dominic. "Translators into the Foreign Language: Charlatans or Professionals?" International Journal of Translation. 4 (1999): 41-67. Web. 22 December 2012.

Stewart, Dominic. "Translation Text Books: Translation into English as a Foreign Language." inTRAlinea (2011). Web. 22 Dec. 2012.

Tratnik, Suzana. "Translation Trouble: Translating Sexual Identity into Slovenian." Contexts, Subtexts and Pretexts: Literary Translation in Eastern Europe and Russia. Ed. Brian James Baer. Amesterdam, Philadelphia: John Benjamins, 2011. 137-48, 95-113. 
Venuti, Lawrence. The Translator's Invisibility. London, New York: Routledge, 1995.

Vieira, Ribeiro Pires Else. Liberating Calibans: Readings of Antropofagia and Haroldo De Campos' Poetics of Transcreation. Post-Colonial Translation: Theory and Practice. Eds. Susan Bassnett and Harish Travedi. London, New York: Routledge, 2002.

Zanettin, Federico. "Bilingual Comparable Corpora and the Training of Translators." META 43.4 (1998). 616-30. 